\title{
Novel Approaches in the Management of Type 2 Diabetes and Associated Vascular Complications
}

\author{
K. V. S. Hari Kumar ${ }^{1}$ \\ 1Department of Endocrinology, Command Hospital, Panchkula, \\ Haryana, India
}

\begin{abstract}
Address for correspondence K. V. S. Hari Kumar, Department of Endocrinology, Command Hospital, Chandimandir, Panchkula, Haryana 134114, India (e-mail: hariendo@rediffmail.com).
\end{abstract}

Ann Natl Acad Med Sci (India) 2021;57:118-121.

\begin{abstract}
Keywords

- gestational diabetes

- insulin resistance

- etiopathogenesis

Diabetes mellitus (DM) is growing in pandemic proportion and affects the affluent and developing nations equally. India has the dubious distinction of being known as the diabetes capital of the world. Epidemiological studies have shown that DM is under diagnosed and inadequately treated in our country. Insulin resistance and $\beta$-cell dysfunction are the two key pathophysiological determinants of the DM. The disease has metamorphosed during the last couple of decades with a significant change in the clinical presentation. Simultaneously, the therapeutic options for the management of DM have also increased in the last decade. This article highlights the research conducted by us over the last decade in the areas of pathogenesis, management, and complications of DM.
\end{abstract}

\section{Introduction}

The global burden of diabetes mellitus (DM) is increasing rapidly posing a significant stress on the health care delivery systems. DM is broadly divided into type 1 (T1DM) and type 2 (T2DM) based on the pathophysiological mechanism of insulin deficiency and insulin resistance (IR), respectively. ${ }^{1}$ India is home to approximately 70 million cases of T2DM and another 80 million are considered to have prediabetes (PD), which is a forerunner of T2DM. Previous studies have shown that the disease is widespread in the community and the visible burden represents just the tip of an iceberg. ${ }^{2}$ Lifestyle modification and regular exercise are the cornerstones of the management in patients with T2DM. ${ }^{3}$ Insulin, sulfonylureas, and metformin are the traditional antidiabetic options and research during the last couple of decades result in the availability of several new drugs. Despite the availability of novel medications, the treatment gap is wide resulting in significant microvascular and macrovascular complications. The clinical outcomes also depend on the awareness about the disease and patient empowerment in dealing with diabetes. ${ }^{4,5}$
We conducted many studies in the areas of epidemiology, pathogenesis, therapeutic options, and the complications of DM during the last decade, which are being presented here.

\section{Etiopathogenesis}

IR leads to T2DM, besides affecting multiple other organs and tissues in the body. ${ }^{6,7}$ The incidence of DM is difficult to determine and many studies have documented the disease burden, as measured by the prevalence of the disease rather than incidence. We studied the incidence of T1DM and T2DM in a cohort 51,217 healthy participants followed for a median duration of 12.5 years with a cumulative follow-up of 613,925 person-years (py). Our data gave an incidence rate of 0.41 per 1,000 py and 2.44 per 100,000 py for T2DM and T1DM, respectively. ${ }^{8}$ Our cohort had low incidence of diabetes in comparison to other participants, which could be due to the healthy lifestyle measures in military service. The adjudication of patients into either T1DM or T2DM is often difficult in lean, young individuals with DM. ${ }^{9}$ The factors that aid in the differentiation are the $\beta$-cell function, IR, published online June 9, 2021
DOI https://doi.org/

10.1055/s-0041-1731146 ISSN 0379-038X

\footnotetext{
(c) 2021. National Academy of Medical Sciences (India).

This is an open access article published by Thieme under the terms of the Creative Commons Attribution-NonDerivative-NonCommercial-License, permitting copying and reproduction so long as the original work is given appropriate credit. Contents may not be used for commercial purposes, or adapted, remixed, transformed or built upon. (https://creativecommons.org/licenses/by-nc-nd/4.0/).

Thieme Medical and Scientific Publishers Pvt. Ltd. A-12, 2nd Floor, Sector 2, Noida-201301 UP, India
} 
and autoimmune antibody markers. We studied the etiopathogenetic markers in nonobese patients, aged younger than 35 years with DM. ${ }^{10}$ Autoimmunity was diagnosed using glutamic acid decarboxylase 65, insulin autoantibody, and islet cell antibody. Homeostasis model assessment (HOMA) models of HOMA-beta and HOMA-IR were used for estimation of $\beta$-cell function and IR, respectively. Our results showed that T2DM was the most common etiology even in lean, young adults in India.

The presence of diabetes in patients with pancreatic disorders is classified as Type 3c DM. Visceral adipose tissue (VAT) is a risk factor for T2DM and the same was not evaluated in patients with chronic pancreatitis (CP). We studied 102 patients with $\mathrm{CP}$ and showed that VAT was high in patients with DM than those without DM. ${ }^{11}$ Our seminal study concluded that VAT determines the development of diabetes, even in patients with $\mathrm{CP}$. In the same group, we compared the body fat estimation using dual-energy X-ray absorptiometry (DXA) and bioelectrical impedance analysis techniques and showed that DXA was better. Vitamin D deficiency (VDD) is inversely associated with IR and recent reports suggest that VDD exacerbates the dysglycemia. We studied the prevalence of VDD across the spectrum of glucose intolerance in normal, PD, and T2DM patients and showed that VDD is irrespective of the underlying glucose. ${ }^{12}$ Insulin requirement varies between patients and the etiopathogenesis behind the excessive insulin requirement has not been studied. ${ }^{13}$ We stratified patients based on the total daily insulin requirement (TDIR) into three groups: Group 1 (TDIR <1 U/kg), Group 2 (TDIR 1-2 U/kg), and Group 3 (TDIR $>2 \mathrm{U} / \mathrm{kg}$ ) and studied their clinical profile and carbohydrate consumption. ${ }^{14}$ Patients in the third group had lower body weight and highest carbohydrate consumption when compared with the other two groups. The clinical implication is to limit the carbohydrate intake in patients with high insulin requirement.

\section{Management}

The initial management of DM involves lifestyle modification and pharmacotherapy is for patients with poor control despite intense lifestyle measures. The therapy involves progressive up titration starting with a single oral agent, multiple oral agents followed by the use of insulin, in single or multiple doses. ${ }^{15}$ The ideal metabolic control includes HbA1c $<7 \%$, blood pressure $<130 / 85 \mathrm{~mm} \mathrm{Hg}$, and low-density lipoprotein cholesterol (LDL-C) of less than $70 \mathrm{mg} / \mathrm{dL}$, popularly known as the $A B C$ of diabetes. We studied the prevalence of patients reaching the $A B C$ goals in a sample of 1,000 patients (531 males:469 females). Our data showed that only 90 patients ( $9 \%$ ) achieved the three-part $A B C$ goal $^{16}$ and highlights the urgent need to improve the quality of diabetes care in our country. Bariatric surgery is dubbed as the metabolic surgery for the numerous metabolic benefits. We studied the effects of a novel metabolic surgery (ileal interposition along with sleeve gastrectomy) in a sizeable cohort of patients with T2DM. Our initial data of 10 patients showed remission of DM and hypertension with significant weight loss. ${ }^{17}$ Encouraged by our preliminary data, we included more patients and extended our follow-up. ${ }^{18}$ Further, we modified the surgical procedure to include diverted sleeve gastrectomy in a selected number of patients. ${ }^{19}$ Remission of diabetes is seen in more than $60 \%$ of patients with extensive variability in the remission rates between different surgical procedures. We developed an easy scoring system to predict the probability of diabetes remission after metabolic surgery using our cohort of patients. ${ }^{20}$ The diabetes remission score includes seven clinical variables and is a widely useful tool to predict the postoperative diabetes remission.

Incretin-based therapies are known to have pleotropic benefits in T2DM but have not been studied in new-onset T1DM. We investigated the effect of exenatide and sitagliptin along with insulin in patients with new-onset T1DM and showed that incretin modulators decreases insulin requirement without increasing the hypoglycemic events. ${ }^{21}$ Intravenous insulin is the cornerstone in the management of DM in the intensive care unit (ICU). We studied the efficacy of an incretin modulator, liraglutide in the ICU. In a prospective, open-labeled, randomized study, we showed that liraglutide is a viable alternative to insulin for glycemic control in the ICU with reduced risk of hypoglycemia. ${ }^{22}$ Dipeptidyl peptidase-4 inhibitors (DPP4i) are oral hypoglycemic agents and are thought to be beneficial in the early stages of diabetes only. In a retrospective analysis, we showed the benefits of DPP4 i in longstanding T2DM and concluded that these drugs are beneficial irrespective of the duration of diabetes. ${ }^{23}$

\section{Complications}

The morbidity and mortality in DM are due to either microvascular (retinopathy, neuropathy, and nephropathy) or macrovascular (cerebrovascular, coronary, and peripheral arterial) complications. ${ }^{24,25}$ Hyperglycemia is the key for microvascular complications, whereas the macrovascular complications are aggravated by multiple factors besides hyperglycemia alone. We studied the clinical profile of microvascular complications in a large sample (1,500 patients) and suggested that the microvascular complications are seen in about half of the patients and are aggravated by advanced age, longstanding diabetes and poor glycemic control. ${ }^{26}$ We showed that neuropathy was the most common type and nephropathy was associated strongly with retinopathy. Gestational diabetes mellitus (GDM) is characterized by transient hyperglycemia with similar risk factors of that of T2DM. ${ }^{27}$ During the development of vascular complications, functional changes precede the structural changes. We evaluated for early retinopathy using the visual evoked potential (VEP) in patients with GDM and T2DM. ${ }^{28}$ VEP was recorded to derive the prominent positive peak latency (P100), amplitude, and initial negative deflection (N75) latency. The data were compared with 10 gestational age matched controls with normal glucose tolerance. The P100 latencies were comparable among the three groups (GDM, T2DM, and controls). However, patients with any diabetes (GDM and T2DM) had prolonged P100 latencies and low P100 amplitudes in comparison to controls. Our data showed that VEP abnormalities are detectable even in the short-term hyperglycemia of GDM. 
T2DM patients are prone to infectious and inflammatory disorders, which are often resistant to conventional therapies. ${ }^{29,30}$ Acquired perforating dermatosis (APD) is an uncommon skin disorder seen in patients with DM and chronic kidney disease. ${ }^{31}$ We analyzed the clinicopathological features of APD and the majority had a subtype of reactive perforating collagenosis and all the patients showed resolution with topical glucocorticoids. T2DM is an independent risk factor for uric acid nephrolithiasis and obesity augments this risk. In a study of 25 patients with DM, we showed that low urine $\mathrm{pH}$ as the main risk factor for uric acid nephrolithiasis and obesity further accentuates this risk. ${ }^{32}$ We demonstrated the beneficial role of botulinum toxin in resistant cases of meralgia paresthetica, which is a form of cutaneous neuropathy. ${ }^{33}$ Telemedicine is developed to bridge the gap in health care delivery systems and we studied the role of telemedicine in screening for diabetic retinopathy in a sample of 196 males and 269 females with T2DM. ${ }^{34}$ Non-high-density lipoprotein cholesterol (non-HDL-C) is gaining importance over LDL-C as a cardiovascular risk marker in patients with T2DM and our data suggest a significant discordance between the LDL-C and non-HDL-C. ${ }^{35}$ The cardiovascular risk could also be aggravated by a combination of the gliptins with certain antihypertensive drugs such as angiotensin-converting enzyme inhibitors. ${ }^{36}$

\section{Conclusion}

To conclude, the burden of DM requires a multidisciplinary approach involving extensive public and private partnership. Our research attempts to fill certain gaps in the understanding about diabetes and are relevant to the Indian population. Increasing the focus on noncommunicable diseases and patient empowerment are the important keys to contain the diabetes-related morbidity and mortality.

\section{Note \\ Dr. J.S. Bajaj's oration delivered during NAMSCON 2020.}

\section{Conflict of Interest}

None declared.

\section{References}

1 Hari Kumar KVS. The good, the bad, and the ugly facets of insulin resistance. Med J Armed Forces India 2020;76(1):4-7

2 Hari Kumar KVS, Misra A. Endocrine and diabetes research from SAARC (South Asian Association for Regional Cooperation) countries. Indian J Endocrinol Metab 2013;17(5):950-951

3 Kalra S, Hari Kumar KVS. Seven sinful sisters: seven smart solutions to stop diabetes. J Pak Med Assoc 2018;68(11):1727-1728

4 Hari Kumar KVS, Gupta AK, Kumar A. Attitude of health care professionals about the diabetes from India. J Soc Health Diabetes 2014;2:92-95

5 Hari Kumar KVS, Kumar S, Anish SR, Pillarisetti S. Assessment of diabetes empowerment amongst patients from India. J Soc Health Diabetes 2014;2:77-81

6 Hari Kumar KVS, Manrai M, Sood AK, Sharma R. A clinical study of insulin resistance in patients with chronic pancreatitis. Diabetes Metab Syndr 2017;11(Suppl 1):S283-S286
7 Kumar HK, Yadav RK, Prajapati J, Reddy CV, Raghunath M, Modi KD. Association between thyroid hormones, insulin resistance, and metabolic syndrome. Saudi Med J 2009;30(7):907-911

8 Hari Kumar KVS, Patnaik SK. A long term follow-up study from India assessing the risk of diabetes mellitus in service population. Diabetes Metab Syndr 2018;12(2):87-90

9 Hari Kumar KVS, Priya S, Shaikh A, Prusty P. Diabetes in young-unusual case presentation. J Pediatr Endocrinol Metab 2011;24(7-8):581-583

10 Kotwal N, Upreti V, Hari Kumar KVS, Nachankar A. Etiopathological differentiation of diabetes mellitus in lean, young adults. Diabetes Metab Syndr 2017;11(Suppl 2): S771-S774

11 Hari Kumar KVS, Sharma R, Manrai M, Sood AK. Visceral adipose tissue as a risk factor for diabetes mellitus in patients with chronic pancreatitis: a cross-sectional, observational study. Diabetes Ther 2017;8(5):1057-1064

12 Modi KD, Ahmed MI, Chandwani R, Hari Kumar KVS. Prevalence of vitamin D deficiency across the spectrum of glucose intolerance. J Diabetes Metab Disord 2015;14-54

13 Hari Kumar KVS, Kumar S. Amenorrhea, ptosis and high insulin requirement in a young girl. Diabetes Metab Syndr 2016;10 (1, suppl 1) :S151-S153

14 Hari Kumar KVS, Gupta AK, Kumar A. Clinical profile of patients using normal, high and very high insulin doses in type 2 diabetes. Diabetes Metab Syndr 2014;8(2):72-74

15 Hari Kumar KVS, Modi KD, Jha R. Glycemic control in patients of chronic kidney disease. Int J Diabetes Dev Ctries 2007;27:99-103

16 Hari Kumar KVS, Modi KD. A1c, blood pressure and cholesterol goal achievement in patients of type 2 diabetes. Med J DY Patil Univ 2016;9:195-199

17 Hari Kumar KVS, Ugale S, Gupta N, et al. Ileal interposition with sleeve gastrectomy for control of type 2 diabetes. Diabetes Technol Ther 2009;11(12):785-789

18 Kumar Kota S, Ugale S, Gupta N, et al. Remission of type 2 diabetes mellitus by ileal interposition with sleeve gastrectomy. Int J Endocrinol Metab 2011;9(3):374-381

19 Kota SK, Ugale S, Gupta N. Naik V, Hari Kumar KVS, Modi KD. Ileal interposition with sleeve gastrectomy for treatment of type 2 diabetes mellitus. Indian $\mathrm{J}$ Endocrinol Metab 2012;16(4):589-598

20 Ugale S, Gupta N, Modi KD, et al. Prediction of remission after metabolic surgery using a novel scoring system in type 2 diabetes - a retrospective cohort study. J Diabetes Metab Disord 2014;13(1):89

21 Hari Kumar KVS, Shaikh A, Prusty P. Addition of exenatide or sitagliptin to insulin in new onset type 1 diabetes: a randomized, open label study. Diabetes Res Clin Pract 2013;100(2):e55-e58

22 Verma V, Kotwal N, Upreti V, et al. Liraglutide as an alternative to insulin for glycemic control in intensive care unit: a randomized, open-label, clinical study. Indian J Crit Care Med 2017;21(9):568-572

23 Hari Kumar KVS, Gupta AK. Clinical audit of patients using DPP4 inhibitors in longstanding type 2 diabetes. Diabetes Metab Syndr 2015;9(4):277-279

24 Hari Kumar KVS, Bhasker S, Banga PK. Pseudoainhum of toes in type 2 diabetes. Int J Diabetes Dev Ctries 2011;31:241-242

25 Dhull P, Upreti V, Hari Kumar KVS, Patnaik SK. Hemichorea - hemiballismus in nonketotic hyperglycemia. J Acad Med Sci 2012;2:82-84

26 Hari Kumar KVS, Kota SK, Basile A, Modi KD. Profile of microvascular disease in type 2 diabetes in a tertiary health care hospital in India. Ann Med Health Sci Res 2012;2(2):103-108

27 Nachankar A, Kotwal N, Upreti V. Verma V, Hari Kumar KVS Association of vitamin $\mathrm{D}$ and parathyroid hormone with 
insulin sensitivity, beta cell function and gestational diabetes in pregnancy: a cross-sectional, observational study. Diabetes Ther 2018;9(5):2081-2090

28 Hari Kumar KVS, Ahmad FMH, Sood S, Mansingh S. Visual evoked potential to assess retinopathy in gestational diabetes mellitus. Can J Diabetes 2016;40(2):131-134

29 Hari Kumar KVS, Banga PK, Bansal R, Kalia R. Recurrent insulin injection abscesses: atypical etiology. Indian J Endocrinol Metab 2012;16(Suppl 1):S123-S124

30 Hari Kumar KVS, Pandey I, Singh K, Mukherjee D. Unusual presentation of renal tuberculosis in type 2 diabetes. Niger J Clin Pract 2012;15(4):498-499

31 Hari Kumar KVS, Prajapati J, Pavan G, Parthasarathy A, Jha R, Modi KD. Acquired perforating dermatoses in patients with diabetic kidney disease on hemodialysis. Hemodial Int 2010;14(1):73-77
32 Hari Kumar KVS, Modi KD. Analysis of risk factors for uric acid nephrolithiasis in type 2 diabetes. Saudi J Kidney Dis Transpl 2011;22(3):482-487

33 Dhull P, Tewari AK, Upreti V, Prakash MS, Hari Kumar KVS. Botulinum toxin for meralgia paresthetica in type 2 diabetes. Diabetes Metab Syndr 2013;7(1):1-2

34 Modi KD, Chandwani R, Hari Kumar KVS, Ahmed I, Senthil T. Use of telemedicine in remote screening for retinopathy in type 2 diabetes. Apollo Medicine 2015;12:260-263

35 Modi KD, Chandwani R, Ahmed I, Hari Kumar KVS. Discordance between lipid markers used for predicting cardiovascular risk in patients with type 2 diabetes. Diabetes Metab Syndr 2016;10(1(suppl 1):S99-S102

36 Hari Kumar KVS. Sitagliptin and cardiovascular outcomes in type 2 diabetes. N Engl J Med 2015;373(25):2478 